\title{
'The Life That We Don't Want': Using Participatory Video in Researching Violence
}

\author{
Joanna Wheeler
}

Abstract This article reports on the use of participatory video as a research tool for working in violent contexts. The research asked how people living in poor areas of Rio de Janeiro, Brazil can build a bridge between violence and citizenship through participatory social action. Working in violent favelas and housing estates, the process involved creating participatory discussion groups drawn from different segments of the community. Participatory video was one of several tools used in the research process. The main contribution of participatory video was not in generating empirical findings, but in challenging patterns of power and control.

\section{Introduction}

This article draws on eight months of intensive participatory action research in communities in Rio de Janeiro, Brazil, including favelas, ${ }^{1}$ housing estates and a middle class neighbourhood. The central question addressed through this research was how people living in favelas can build a bridge between violence and citizenship through participatory social action. The research posed this question in order to gain an understanding of the ways that this may already occur or what prevents it from occurring. The research also interrogated the question itself, by using a methodological approach that had the potential to reduce violence and contribute to greater citizenship.

Within these highly violent favelas and housing estates, the research process involved creating participatory discussion groups drawn from different segments of the community, and integrating participatory video and theatre at various points. The work was led by a core group of community researchers, themselves active locally in trying to change the situation, with the intention that they assume active leadership of the process. This research approach, which required building trust within the communities and creating a safe space for reflection and discussion around often traumatic and painful experiences, was extremely important given the context. The research was the empirical basis for my own doctoral work, but because of the heavy involvement of community researchers throughout, I refer to the research as a collective endeavour.

This article focuses on the role of participatory video as part of a research process in a violent context. Participatory video was one among several research and action strategies deployed as part of a broader participatory action research project that aimed to explore violence and how people can respond to it. The article will illustrate how using video, adopting a participatory approach to film-making, and working in a violent setting raise additional and more intense methodological challenges than those which might arise in research that does not have these characteristics. In the light of these challenges, this article assesses the role of the participatory video strand within a multistranded methodology. It concludes that, while the methodological challenges are certainly more numerous and complex, participatory video was important in terms of the research process and the social action surrounding it, rather than in terms of the research findings it generated. 


\section{Context}

Rio de Janeiro, with a metropolitan-area population of 13 million, is one of the growing number of 'mega-cities' across the world, where large percentages of the population live in uncertain and poor conditions (Sassen 1994) and illegal housing (Davis 2004). The volume of cocaine being trafficked globally has increased by over 300 per cent in the past 20 years (Moser and Rodgers 2005). Simultaneously, levels of violence in Rio de Janeiro have risen - by over 35 per cent between 1979 and 1998 (Moser 2004). ${ }^{2}$

Meanwhile, between 1993 and 2002, 16,426 people have been 'disappeared' by a combination of drug trafficking groups, the military police, and para-state death squads. Urban political violence in general is all the more pressing because it is directly related to a crisis of legitimacy of political institutions, and to the meaning of citizenship and rights (Isin 2000). Violence perpetrated by drug mafias and the military police in Rio is organised and systematic, and affects different geographic spaces within the city to different degrees. High levels of insecurity and pervasive effects of violence in the favelas and estates where socially excluded groups live are juxtaposed with relative safety and state control in the parts of the city where they work. At the same time, across Brazil's cities, the middle class tends to retreat into fortified complexes, seeking to isolate themselves from the threat of violence and social processes apparently beyond their control (Caldeira 1999). The increasing spatial stratification of security is accompanied by a growing privatisation of security. Middle class residents hire private security forces to protect their property and ensure their safety, while security in favelas is often simultaneously enforced and violated by trafficking groups.

In the favelas and estates, the state is not a powerful actor, and the ability of any part of the state or government to change this situation is limited. Drug trafficking groups and para-police militias have become the dominant powers in these communities (Moser and Rodgers 2005; Moser 2004). Since 2004, militias have been emerging as a new authority within favelas. Traditionally, drug trafficking factions vie with one another for control over lucrative drug sale and distribution points. In 2004, groups of wellarmed men began to invade and take control over favelas, expelling or killing those associated with the locally dominant faction, suppressing open drug trade, and extorting money for 'security' from residents. These 'militias', as the media has labelled them, comprise a mixture of off-duty, retired, or suspended police officers (military and civil), prison guards and firemen. Within two years of taking over the first favela in 2005, the militias controlled 171 communities across the city (UOL Eleicoes 2008).

Research was conducted in Quitungo and Guaporé, and in Santa Teresa. Quitungo and Guaporé is a community made up of two large housing estates and three favelas inhabited by approximately 40,000 people, in the city's largely industrial North Zone. Despite having among the highest levels of violence in Rio, Quitungo and Guaporé have not experienced significant interventions by the government or external NGOs. It is controlled by two different factions of a para-police militia. Santa Teresa is a middle class neighbourhood in the centre of the city, surrounded by favelas dominated by drugtrafficking factions. Several of the favelas are the site of large government-sponsored upgrading projects and other interventions by external NGOs in the past ten years.

\section{Methodology}

The overall research methodology drew on elements of participatory action research and participatory learning and action, which treat research as a process that can create emancipatory knowledge by involving participants as active researchers (Gaventa and Cornwall 2001; Reason and Bradbury 2001; Park et al. 1993; Pretty et al. 1995). In particular, this research was designed to give the participants the opportunity for 'collective self-reflective enquiry ... in order to improve the rationality and justice of their own social ... practices, as well as their understanding of these practices and the situations in which these practices are carried out' (Kemmis and McTaggart 1988: 1, emphasis added).

To address these three foci of participatory action research - practices, understanding and situations - the research process facilitated public debate through participatory discussion groups in public spheres, connecting people of different social class, gender, age and social positioning (Kemmis 2008). We also integrated aspects of participatory urban appraisal (Moser and McIlwaine 1999, 2004; Moser and Holland 
1997) and core elements of feminist methodologies, including attention to the intersection of race, gender and class, and issues of interpretation, translation and representation (Harding and Norberg 2005).

Community researchers - seven in Quitungo and Guapore and three in Santa Teresa - were key actors throughout the research process. All had pre-existing community leadership roles but little or no experience with conventional research. I provided intensive training in participatory research, including basic participatory video and camera skills. These individuals, selected to reflect the diversity of their communities in terms of their demographic profiles and community roles, collaborated in stakeholder analysis, developed research themes, facilitated research meetings, mobilised participants, and helped to create participatory videos.

A range of participatory learning and action methods - such as Venn diagrams, problem tees, calendars, timelines, community mapping, and transect walks - were used during 60 participatory discussion groups with crosssections of the community on themes they identified. Other methods included a questionnaire survey applied to 350 residents, the use of secondary survey data, 30 semistructured interviews, participant observation and several policy dialogue sessions with local, state and federal government and NGO representatives. Video was used as one among many other tools, as a participatory medium for research and transformative action, and also to train researchers and to document the research process and meeting proceedings. At the end, we created three participatory films, addressing the central research question of how violence affects people's lives and what steps they could take to remedy the situation.

As the community researchers became increasingly confident with participatory tools, I assumed a supporting role, among other things facilitating weekly meetings for ongoing analysis and reflection on emerging findings and a final workshop pulling together key results from the participatory discussion groups. Finally, I also provided training in how to use the research results, including discussions on how community researchers could use them strategically in their own work.

\section{Insights from using participatory video in a context of violence}

Participatory video has been used since the 1970 s as one in a range of participatory approaches to development work and more recently as a participatory action research tool. ${ }^{3}$ Some of its advantages are highlighted by Snowden (1984) who pioneered its use in 1967:

The ability to view immediately one's own self speaking on videotape assists individuals to see themselves as others see them. This selfimage conveys the impression immediately that one's own knowledge is important and that it can be effectively communicated. These video techniques create a new way of learning, which not only build confidence, but show people that they can say and do things that they thought were not possible before.

There is a small but growing body of work on participatory video as a research methodology (White 2003). Some of the challenges of using participatory methods in contexts of urban violence have been explored at a general level (Moser and McIlwaine 2004; Moser and Holland 1997). Adapting participatory methodologies particularly participatory video - to violent contexts presents some specific challenges. It is important to note that some of the difficulties arising from using participatory video would apply to any research method, qualitative or quantitative, participatory or not, used in a sensitive context (Lee and Renzetti 1990).

\section{Participatory video as strengthening the research and communication process}

Each of the three films made had a different focus and theme, reflecting the views of the group making it. The creation process was participatory. All participants received training in basic filming skills and put these to use. I trained some of the community researchers in basic editing skills that enabled them to play roles in editing.

While the videos may not directly challenge those responsible for violence, or provide unique empirical insights, the process of making them did give participants a greater degree of control over the research process and communication of findings, and helped build their confidence and their trust in the research process. It also helped create an opportunity for interaction between a diverse group of people who might not otherwise 
have listened to each other's perspectives on the violence which affects them all. A significant dimension to the role of video was the validation of people's perspectives and views through public screenings. The process of interaction that was catalysed through the videos extended understanding and solidarity, and helped provide positive images to challenge negative stereotypes. It also served as a feedback mechanism for research participants. Because of their easy replicability and visual nature, the videos facilitated communication of the research beyond the group immediately involved, including dialogues with policymakers.

Throughout the process of creating the films, participants expressed their perceptions of violence and how it affected them. Many older women saw violence as the result of poor parenting on the part of other women, who they perceived as resistant to advice or criticism. But they also focused on how the effects of violence which they summarised as 'prison, hospital or cemetery' - affected mothers, causing them despair and loss. Children involved in the video process wanted to show how the influence of the wrong kinds of friends could lead to involvement in violence and how the lack of attention of parents and adults and absence of appropriate leisure facilities contribute to the problem. Community leaders focused on how they have tried to counteract the effects of violence and social exclusion, and government's failure to support them in this.

Because the process of creating the films involved a broad spectrum of people, these different views were included to varying degrees in the final products. The need for groups to work together to agree on a single story-line for each film led to some interesting debates about which dimensions of violence they should show. Participatory video offers a way to include 'extended language' in the research process by recording people's emotions, expressions and gestures and allowing them to use this extended language to communicate about the research topic (Ramella and Olmos 2005). Perhaps because of the multiple dimensions of communication involved in the videos, they validated people's views in a way that a workshop or academic paper cannot.

Addressing these topics in this form challenged dominant power holders within the communities only indirectly. The medium of video required a scaling back of risk in what people said and portrayed. Yet at the same time, people were more willing to listen to what others were saying when they watched it on video than they would have in face to face encounters. This kind of listening in such settings is not something that is easily achieved by other methods, even given the limitations.

Labelling by the media, state and NGO actors plays a powerful role in determining broader social perceptions of the problem of violence (Moncrieffe 2008). Favela residents suffer the effects of the labels applied by the media in some instances. During the research process, participants identified the negative labels applied to their community and to specific groups - especially children and young people as a contributing factor to the cycle of violence. These labels also contribute to residents' expectations about how those involved in the violence will behave. Together with the fear and stigma that emerged in the participatory discussion groups, negative labelling by external actors and by residents themselves obstruct attempts to imagine a different pathway that leads out of violence. The issue of labelling cannot be explored in detail here, but the participatory video process provides an interesting opportunity for counter-labelling. Two of the films produced attempted to counter the negative image of the communities by featuring positive examples of citizen action occurring there. A sense of solidarity was created through the films between the groups and communities involved, in the face of shared negative stereotypes. The visual nature and easy distribution of film renders it a potentially powerful medium for counter-labelling, as became clear to the participants, who rated this as a strength of the films.

Another role of the video was providing almost instant feedback to research participants - an important ethical obligation in a participatory research process. We screened footage from participatory discussion groups on the same day for those involved. Copies of the films were distributed to all participants; community leaders showed the film on a course about working with the police to reduce violence, and other leaders became interested in replicating the process as a result. 
The films helped to communicate the research to a range of audiences, and their efficacy at doing so proved to be a major contribution of the method. Having used the films to illustrate how they were trying to address violence and to counter wholly negative labels and stereotypes, the participants closed them with messages addressed directly to parents, children and the government, on how to reduce the violence.

In particular, the films caught the attention of policymakers. We used them to open a debate with a panel of policymakers including a community leader, City Councillor and representative of the Federal Ministry of Culture. The audience included community residents involved in making the films, community activists and representatives of NGOs, the state and city government. The films framed the debate in a way which would have been difficult to achieve through more conventional presentations or dialogue. As a result of the debate, the city councillor launched a programme using participatory video in over 40 communities across the city. The films have been used to communicate the research to other researchers in an international research network, enriching comparisons of our experiences across contexts.

While it may have been possible to effectively communicate the research to policymakers and provide feedback to the communities involved without using video, participatory video certainly enhanced both of these dimensions of the research.

\section{Limitations of using participatory video to research violence}

In a context of fear and mistrust caused by violence, the public nature of video limits what people are able to say. Because of a history of frequent shifts in the violent control of the community, extreme caution is needed in what one says and to whom. This is a significant barrier in any kind of empirical research in contexts of violence. The level of trust between the researcher and the research participants directly affects the type of information that will arise. As one woman explained:

Before [when the drug traffickers were in control] we did not have freedom of expression, we couldn't have friendships. You never knew when one word that you said to someone on the street two kilometres from here might be taken the wrong way, reported back to the traficantes (drug traffickers), and your life would be over.

(From Wheeler 2006)

Fear and mistrust between residents, and the self-censoring that results, is replicated in all their interaction with people from outside the community. On many occasions, I observed residents expressing one opinion publicly, while saying something very different to me privately, or changing the way they described a given situation according to who was present. The norms and rules governing what can be said and to whom are complex, yet well understood by residents. Hence the importance of the research being led by community researchers who could navigate these norms and rules so as to create what felt like relatively safe spaces for community residents to participate and reflect on their experiences.

Self-censorship and the expressing of different and even contradictory opinions are tendencies to which the external researcher needs to be attentive in any kind of research, but particularly in a violent context. People do not say what they think for a variety of different reasons, and social research has to contend with a constant cycle of 'editing out', made more acute in participatory research because of its interactive and relatively public nature. During the quantitative portion of this research project, people were less open and willing to talk about issues that arose during the qualitative, participatory portion of the research. This reticence might be attributed to several factors. Participants may say what they think an outsider wants to hear; this 'interviewer effect' is well documented for all qualitative research (Singer et al. 1983). People may be afraid or reluctant to talk about something because of possible repercussions, or because they have a vested interest, such as family members or they themselves being involved in drug trafficking. The 'fixedness' of people's voice in video makes these issues more acute with participatory video: while participants may control the process, they cannot fully control the output. Once the videos are made and copies distributed within the community, the video can be seen by anyone anywhere. This is very different from an interview or a questionnaire, where anonymity is more plausible. This heightens some of the risks arising from using video as a research tool on violence. 
During a filmed transect walk, for example, community researchers asked only the most banal questions of the residents they encountered. They avoided any mention of violence, power or anything that could be remotely connected to these topics. They also avoided filming any areas that could be perceived as sensitive, such as the gates and barriers installed by the militia and any part of the boca de fumo (points of sale for drugs). In the films, violence was addressed obliquely, without apportioning blame, despite the strong opinions that many people had about which actors were responsible. The issue of who is responsible for the violence is an extremely sensitive one, and declaring a position could pose a significant risk for any of the residents. One film, 'The Life That We Don't Want', portrayed how children become involved in violence and how this affects families, but never mentions drug trafficking or the militia. Violence is treated as disembodied: something which blights the community but has no face or name. This was a deliberate silence.

During discussion groups, people made more direct references to the drug traffickers and the militia, but still often using a kind of code. In a children's session on citizenship, we asked them to list examples of things that are not citizenship. Many responded, 'Paying 10 reais', which is a reference to paying the militia for protection. Even though community members used video as a tool for potentially reducing violence - through the messages they incorporated addressed at children, parents and the government - the films did not enable them to show the details and specifics of violence. This is another limitation of video in an insecure context: violence can only be described or acted, but not fully represented.

Interpersonal dynamics between community researchers themselves and between the researchers and the research participants also shaped the participatory quality of the research and the videos it generated. It is difficult to ascertain how representative and inclusive participation was from within the community, because those who participated reflected the social circles and connections of community researchers. The micro-politics of the community, which may have no relationship to the research topic itself, thus indirectly affect the research process. This kind of contingency is a feature of all participatory research, because it is a part of the social fabric that, in a participatory process, is purposefully not excluded.

In fact, through taking account of the social fabric, a participatory process can exacerbate exploitation and existing exclusions within the community, a risk heightened by the nature of the technology involved in videoing. During the video process, disputes arose about who controlled the technology, where the camera was kept, who had access to it, when it could be used, which parts of the community were filmed and when. In those disputes, various accusations were made of discrimination because of gender, age and location in the community.

The editing process was the most technically difficult, and very time-consuming. It was also the part of the participatory video process that required the most intensive intervention by me as the external facilitator. The nature of digital video editing makes it practically impossible to make the editing process participatory. Literacy can be a significant obstacle in research, and participatory video demands another layer of technical literacy. In the end, we settled for approximate participation involving a small number of people at each stage of editing. Editing would almost certainly be the biggest barrier for community researchers to use participatory video on their own, partly because of the need for technical knowledge, and partly because it was the stage that led to biggest disagreements within the group.

The process of creating a video with a single narrative implies reconciling the different agendas of those involved in the process. In the end, these different agendas were not wholly reconciled. The risk is that the video becomes reductive and superficial, but still evocative, therefore misrepresenting the situation. Certain things had to be cut out due to time limits and there were disagreements about what to leave out and what focus to give each of the films. These disagreements partly reflected underlying differences over the purpose of the film - for example, should the film showcase the strengths of the community or focus on its problems? My own agenda was for the films to flow from research process and to address the central research questions - and this was not necessarily the top priority for all participants, not least 
because the research questions addressed very painful issues. Many participants found it difficult to respond to them, let alone to film their views for public consumption.

The role of the facilitator is crucial in addressing these problems, and what appeared in the final films represented the facilitators' best efforts to balance different perspectives. I provided several opportunities for training in video and facilitation, both formal and informal, for the community researchers and research participants. However, there was still a need for ongoing accompaniment and support throughout the video process, especially editing, when the technical support I provided often consisted of carrying out the actual editing with one or two participants guiding my choices. My role was often that of arbitrator, helping participants to reconcile differences or conflicts about the video. An engaged and supportive facilitator is essential, both in terms of the interpersonal dynamics, but also in terms of technical difficulties that may emerge. In summary, the experience demonstrated how existing dynamics within the community as well as the technology itself can constrain the participatory nature of video.

In violent contexts, the micro-politics and interpersonal dynamics between people involved can take on even greater significance than in non-violent research contexts, since the threat of violence and its repercussions shapes people's interactions and conversations on a daily basis. Violence is fundamentally an issue of life and death, and this creates special considerations for researching it.

This feature of the daily life of people living in violent contexts is an obstacle for participatory research, which can only ever be partially overcome. How the violent context influences interactions, and how the micro-politics and interpersonal dynamics of those involved limit the degree of participation across different sections of the community, are important aspects to reflect on, not only for reasons related to research quality criteria but also because they probably constrain the scope for the research process to unleash broad-based social action to reduce violence.

\section{Conclusion}

The main role of participatory video in this research was not to generate unique empirical findings. Rather, the main contribution of participatory video was to challenge patterns of power and control, through the process involved in making and using films. It eased the research process by giving participants a greater degree of control over the outputs, building their selfconfidence, stimulating their enthusiasm for being involved, and contributing to a sense of solidarity and the possibility for countering negative labels. It shaped some of the findings because when the cameras were recording, people decided how to present themselves and what to say, knowing that it would be captured on film and shown to a variety of audiences. It generated a format for the findings that was a good medium for providing feedback in ethical and transparent fashion to participants and research teams; and made it easier to attract policymakers' and others' attention to the research and expanded the audiences reached through the research.

However, using participatory video probably also exacerbates the already difficult task of holding open discussions about sensitive topics, especially given the mistrust and fear generated by violence. It adds a layer of technological literacy to the research process which can heighten exclusion. Through disputes over control of the technology and the filming process, participatory video can reinforce existing hierarchies.

Fundamentally, participatory video cannot be understood simply as a means of communicating visually about research. It involves a whole series of processes that are linked to power, exclusion, fear, mistrust and voice, and should be used to research violence only with caution. 


\section{Notes}

1 Slum or squatter settlements.

2 Luke Dowdney, in his detailed study of children involved in the drug trade in Rio de Janeiro, estimates that it employs approximately 10,000 people (Dowdney 2003). Homicides have increased from 9/100,000 in 1983 to $51 / 100,000$ in 2002, although this is as high as 90/100,000 in some areas of the city (Iulianelli et al. 2004).

\section{References}

ActionAid (2002) 'Participation - Poor People's Representation. A Promise Unfulfilled?', DVD, Sierra Leone: ActionAid

Caldeira, Teresa (1999) 'Fortified Enclaves: The New Urban Segregation', in James Holston (ed.), Cities and Citizenship, Durham: Duke University Press

Davis, Mike (2004) 'Planet of Slums: Urban Involution and the Informal Proletariat', New Left Review 26.4: 5-24

Dowdney, Luke (2003) Children of the Drug Trade: A Case Study of Children in Organised Armed Violence in Rio de Janeiro, Rio de Janeiro: 7 Letras

Gaventa, John and Cornwall, Andrea (2001) 'Power and Knowledge', in Peter Reason and Hilary Bradbury (eds), Handbook of Action Research: Participative Inquiry and Practice, London: Sage

Harding, S. and Norberg, K. (2005) 'New Feminist Approaches to Social Science Methodologies: An Introduction', Signs: Journal of Women in Culture and Society 30.4: 2009-2015

Isin, Engin (ed.) (2000) Cities, Citizenship and Democracy, New York: Routledge

Iulianelli, Jorge Atilio Silva; Guanabara, Luiz Paulo; Fraga, Paulo Cesar Pontes and Blickman, Tom (2004) A Pointless War: Drugs and Violence in Brazil, Amsterdam: Transnational Institute

Kemmis, Stephen (2008) 'Critical Theory and Participatory Action Research', in Peter Reason and Hilary Bradbury (eds), Handbook of Action Research: Participative Inquiry and Practice, London: Sage

Kemmis, Stephen and McTaggart, Robin (1988) The Action Research Planner, Geelong, Victoria: Deakin University Press

Lee, Raymond and Renzetti, Claire (1990) 'The Problems of Researching Sensitive Topics: An Overview and Introduction', American Behavioral Scientist 33.5: 510-28
3 For example, ActionAid (2002) used participatory video as part of a three-year action research project in Malawi linking villages to policymakers in the national government and international donors.

Moncrieffe, Joy (2008) Making and Unmaking the Young Shotta [Shooter]: Boundaries and (Counter)Actions in the 'Garrisons', IDS Working Paper 297, Brighton: IDS

Moser, Caroline (2004) 'Urban Violence and Insecurity', Environment and Urbanisation 16.2: 3-16

Moser, Caroline and Holland, Jeremy (1997) Urban Poverty and Violence in Jamaica, Latin American and Caribbean Studies Series, Washington DC: World Bank

Moser, Caroline and McIlwaine, Catherine (2004) Encounters with Daily Violence in Latin America: Urban Poor Perceptions from Colombia and Guatemala, New York: Routledge

Moser, Caroline and McIlwaine, Catherine (1999) 'Participatory Urban Appraisal and Its Application for Research on Violence', Environment and Urbanisation 11.2: 203-26

Moser, Caroline and Rodgers, Denis (2005) Violence and Insecurity in Non-conflict Situations, ODI Working Paper 245, London: ODI

Park, Peter; Brydon-Miller, Mary; Hall, Budd and Jackson, Ted (eds) (1993) Voices of Change: Participatory Research in the United States and Canada, Westport CT: OISE Press

Pretty, Jules; Guijt, Irene; Scoones, Ian and Thompson, John (1995) A Trainer's Guide for Participatory Learning and Action, IIED Participatory Methodology Series, London: IIED

Ramella, Marcelo and Olmos, Gonzao (2005) 'Participant Authored Audiovisual Stories (PAAS): Giving the Camera Away or Giving the Camera A Way?', London School of Economics and Political Science Papers in Social Research Methods, Qualitative Series 10, London: LSE

Reason, Peter and Bradbury, Hilary (eds) (2001) Handbook of Action Research: Participative Inquiry and Practice, London: Sage

Sassen, Saskia (1994) The Global City: London, New York, Tokyo, Princeton: Princeton University Press 
Singer, Eleanor; Frankel, Martin R. and Glassman, Marc (1983) 'The Effect of Interviewer Characteristics and Expectations on Response', The Public Opinion Quarterly 47.1: 68-83

Snowden, Donald (1984) Eyes See; Ears Hear, www.fao.org/sd/CDdirect/CDre0038.htm (accessed 4 June 2008)
UOL Eleicoes (2008) http://eleicoes.uol.com.br/ 2008/ultnot/rio-de-janeiro/2008/07/30/ ult6022u34.jhtm (accessed 26 January 2009) Wheeler, Joanna (2006) Fieldnotes, 10 December White, Shirley (ed.) (2003) Participatory Video: Images that Transform and Empower, London: Sage 